\title{
Construção técnico-política de governança metropolitana
}

\author{
The technical-political construction \\ of metropolitan governance
}

Maria do Livramento Miranda Clementino

Lindijane de Souza Bento Almeida

\section{Resumo}

0 artigo tem como objetivo discutir uma teoria pertinente à análise dos problemas de planejamento e gestão metropolitana, partindo da ideia de "planejamento adaptativo" (Clementino e Almeida, 2011) e do conceito de "mal público metropolitano" desenvolvido por Lacerda (2011) na formulação de um modelo de ação coletiva metropolitana. Propõe a inclusão de um novo elemento no "balanço global positivo de gestão" de Matus (1996) para analisar a cooperação intergovernamental para solução de problemas comuns, particularmente no Brasil, e como solucionar o "mal público metropolitano". A expectativa é a de contribuir para o debate da governança urbana e metropolitana na América Latina a partir de uma nova concepção que tem como base de sustentação teórico-metodológica o conceito de ação coletiva elaborado a partir da sistematização e recorte de uma literatura atualizada.

Palavras-chave: planejamento governamental; governança metropolitana; ação coletiva; Natal/ RN; Brasil.

\section{Abstract}

This article aims to discuss a pertinent theory to the analysis of problems concerning metropolitan planning and management. It starts from the idea of "adaptive planning" (Clementino and Almeida, 2011) and from the concept of "mal público metropolitano" (public problems that spread over the metropolitan space) developed by Lacerda (2011) in the formulation of a collective action model for metropolitan areas. It proposes the inclusion of a new element in Matus' (1996) "overall positive management balance" in order to analyze intergovernmental cooperation for the solution of common problems, particularly in Brazil, and to propose ways to solve the "mal público metropolitano". The expectation is to contribute to the debate about urban and metropolitan governance in Latin America based on a new conception that is theoretically and methodologically supported by the concept of collective action, developed from systematization and from relevant and up-to-date literature.

Keywords: governmental planning; metropolitan governance; collective action; Natal/State of Rio Grande do Norte; Brazil. 


\section{Introdução}

Neste artigo, o tema dos desafios urbanos da cidade contemporânea tem como foco o planejamento e a gestão governamental das cidades, em especial, das metrópoles latino-americanas e brasileiras. A expectativa é a de contribuir para esse debate a partir da sistematização e recorte de uma literatura atualizada associada ao nosso repertório de pesquisa desenvolvido no Núcleo Natal do INCT - Observatório das Metrópoles.

Partimos da premissa de que há atualmente um virtual consenso de que nas sociedades complexas, como a brasileira, o governo está longe de ter sozinho o poder sobre os rumos da cidade. Cabe-lhe, sem dúvida, um papel de liderança e aglutinação de aliados para elaboração de agendas mínimas, e a formação de coalizões que tenham legitimidade para implementar as mudanças nas várias áreas de sua competência formal. Na área da política pública urbana e metropolitana, os padrões de decisão e interação política devem buscar combinar graus de complexidade técnica com a centralidade do próprio objeto de decisão (da política pública): a cidade metropolitana (Andrade e Clementino, 2007).

Em geral, na América Latina e no Brasil, o corpo técnico é mobilizável uma vez que temos inteligência e repertório acumulados. No entanto, o planejamento estratégico participativo é de opção dos governantes, o que tem tornado as escolhas no processo decisório problemáticas quando centralizadas somente no saber técnico. Melhorar esse quadro requer um equilíbrio técnico-político que tenha por referência a ação coletiva e o planejamento participativo.
Com certeza, esse caminho equilibraria tão importante arena pública. E na nossa visão o planejamento governamental teria relevância para mudar essa arena decisória e consequentemente a qualidade da gestão, uma vez que é, e deve ser, visto como um processo técnico e político, podendo ser utilizado como instrumento válido no exercício democrático.

0 Estado moderno foi concebido para desempenhar papéis claramente definidos, como criar condições para o processo de produção e reprodução do capital, assim como criar as condições políticas da existência de um governo que garanta a estabilidade desse Estado. Ele se realiza através de governos, ou seja, o Estado se corporifica através de instituições de governo, ou melhor, dos órgãos que institucionalmente têm o exercício do poder. Dessa forma, a legitimidade do Estado tem a ver com a legitimidade dos governos. 0 poder de Governo está extremamente associado à noção de Estado, à medida que as instituições de governo que organizam a política da sociedade exprimem a orientação política do Estado.

Como o Estado se constituiu na perspectiva de uma Nação, a ação do Estado é uma ação primordialmente voltada para a dimensão interna do território nacional, do controle político, da estabilidade econômica e do bem-estar social. Nesse sentido, a ação dos governos é fundamental para entender a força ou fragilidade do Estado, ou dizendo de outra forma, a eficácia ou ineficácia desse Estado, no sentido de responder as questões provenientes da sociedade. Isso porque o grau de sustentação do Estado está diretamente relacionado com a ação dos governos. Logo, estudar o desempenho de governo através do planejamento e gestão urbana, gestão das cidades e das 
metrópoles, é de significativa importância para se ter uma noção mais clara da capacidade do Estado de enfrentar os problemas que a sociedade coloca.

0 artigo propõe que o planejamento governamental cooperativo ajudaria a recuperar certa visão compreensiva para um número limitado de questões consideradas estratégicas pela sociedade organizada, governo federal, governo estadual, municípios (metropolitanos) e agências públicas, concentrando esforços nos "gargalos" e abrindo mão de tudo querer planejar nos mínimos detalhes. Poderíamos denominar essa estratégia "planejamento adaptativo", ou como quer Carlos Matus, "planejamento estratégico situacional" que, segundo ele, deve ser "o cálculo que precede e preside a ação" (Matus, 1996).

Na nossa visão, o plano de governo na perspectiva do "planejamento adaptativo" teria a relevância de mudar a arena decisória e, consequentemente, reverter a má qualidade da gestão e estabelecer a boa governança. Como todo processo político o momento do planejamento é um espaço privilegiado de negociação entre atores públicos e sociais. Há os que vão mais longe afirmando tratar-se também de um momento de "educação pela cidadania". E o primeiro pressuposto para a implementação da boa governança urbana é a participação, muito embora saibamos que na prática ela apresenta limites para integrar as prescrições da boa governança. Sendo pois ao mesmo tempo processo e instrumento. Logo, uma forma estruturada de tomar decisões de acordo com as expectativas da sociedade.

No Brasil, a falta que faz o planejamento das áreas metropolitanas, por exemplo, tem dificultado a criação de um espaço privilegiado de negociação entre atores sociais e políticos, confrontando e articulando interesses e alternativas para a sociedade. Na visão de Clementino (2008), o plano metropolitano deve assegurar a ampla mobilização e participação de todos os interessados na discussão, na negociação e na tomada de decisões. Trata-se de alternativa política (e também técnica) de negociação e decisão coletiva, compartilhada sobre o futuro comum dos municípios metropolitanos. Nesse sentido, o ordenamento e o planejamento territorial representam contribuição fundamental para a capacitação e o desenvolvimento sociopolíticos da sociedade desde que seja resultante de um processo de dimensões ao mesmo tempo técnica e política.

A especificidade das diferentes realidades das áreas metropolitanas no Brasil, que envolvem inúmeros problemas de interesse comum, exige um planejamento específico e um balanço de governança da "cidade metropolitana" (Borja e Castels, 2004) que levem em conta sua grande complexidade e que combinem os princípios de eficiência no desenvolvimento das atividades econômicas, de qualidade de vida adequada para seus habitantes, de qualidade de desenho urbano e controle e preservação (na medida do possível), de um meio ambiente submetido a uma contundente ação humana. Daí, a necessidade em concentrar-se nessa escala em projetos estruturadores que orientem uma visão de futuro, de longo prazo, de modo a evitar o imediatismo dos governos e ações meramente compensatórias e reparadoras.

0 artigo tem como objetivo discutir uma teoria pertinente à análise dos problemas de planejamento e gestão metropolitana, partindo da ideia de "planejamento adaptativo" 
(Clementino e Almeida, 2011) e do conceito de "mal público metropolitano" desenvolvido por Lacerda (2011) na formulação de um modelo de ação coletiva metropolitana. Propõe a inclusão de um novo elemento no "balanço global positivo de gestão" de Matus (1996a) para analisar a cooperação intergovernamental para solução de problemas comuns, particularmente, no Brasil de modo a evitar a ocorrência do "mal público metropolitano". A expectativa é a de contribuir para o debate da governança urbana e metropolitana na América Latina a partir de uma nova concepção que tem como base de sustentação teórico-metodológica o conceito de ação coletiva elaborado a partir da sistematização e recorte de uma literatura atualizada associada ao nosso repertório de pesquisa desenvolvido no Núcleo Natal do INCT - Observatório das Metrópoles.

\section{Estratégias de planejamento governamental para o "bom governo"}

Para se analisar um momento político - um período de governo -, é importante ter presente que os grandes atores que participam da estrutura do poder têm objetivos e atuam estrategicamente com vistas à realização de seus objetivos. Dessa forma, os governantes devem ter como seu objetivo principal a criação de estratégias que garantam a manutenção do equilíbrio, de forma que seja possível realizar um bom governo.

Para a garantia desse equilíbrio de governo, através do planejamento governamental num contexto democrático, como a que este estudo pretende desenvolver, Matus (1996a)

\title{
Modelo de Análise
}

\author{
P - Projeto de Governo
}

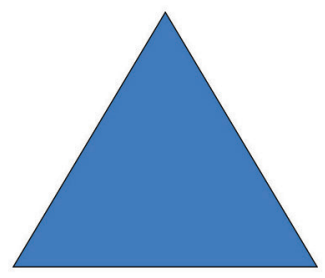

- G - Governabilidade do Sistema

C - Capacidade

de Governo 
sugere três elementos, os quais precisam ser levados em consideração para que seja possível realizar um bom governo: o projeto de governo, a governabilidade do sistema e a capacidade de governo. 0 pressuposto básico é que o exercício de governo exige que constantemente se articulem três variáveis, constituindo um sistema triangular no qual cada uma depende das demais. Esses três elementos são interligados, e o governante tem por desafio justamente manter o equilíbrio necessário entre eles de forma a que seja possível ter capacidade propositiva, realizar ações com o apoio da sociedade e ter métodos de planejamento que eleve a qualidade de sua gestão, ou seja, melhore a capacidade de governo.

É interessante chamar a atenção para o fato de que o autor introduz na discussão a importância que a dimensão política tem sobre a dimensão técnica para garantir a sustentação de uma gestão. Isso porque a abertura dos espaços de governo, no sentido da democratização, é um elemento crucial para a sustentabilidade do projeto de governo. 0 governante não deve atuar numa só dimensão, enfatizar, por exemplo, a dimensão técnica e não compreender a dimensão política legitimadora da sociedade. Isso significa dizer que Matus compreende a gestão não esquecendo, em nenhum momento, a dimensão política da mesma, ou seja, a relevância do controle das situações políticas para viabilizar ou não um projeto de governo.

Segundo Matus, em termos gerais, o projeto de governo, um dos elementos do exercício de governo, diz respeito ao conteúdo propositivo dos Projetos de Ação que um ator propõe-se realizar para alcançar seus objetivos. A discussão sobre o projeto de governo versa sobre o tipo de sociedade, as reformas políticas, o estilo de desenvolvimento, etc., que parecem pertinentes ao caso e ao grau de governabilidade do sistema (Matus, 1996a, p. 51). Logo, para uma discussão sobre gestão, se faz necessário conhecer os elementos que dão origem às ações, o que possibilita uma compreensão mais adequada da realidade. Dessa forma, em qualquer campo de análise governamental se torna impossível trabalhar desconhecendo o conteúdo do projeto de governo, ou seja, que mudanças, no presente, estão sendo propostas para que exista um futuro que seja diferente, que seja capaz de controle.

Um outro aspecto importante a ser considerado é a governabilidade do sistema que, em última instância, diz respeito à capacidade política de governar, que se relaciona com a capacidade de obter apoios, de conseguir a confiança, da sociedade organizada e dos partidos políticos. Confiança que, segundo Putnam (1996), gera ações cooperativas que influenciam as perspectivas de um governo eficaz. A partir do momento em que o governante tem a capacidade de estabelecer uma certa relação de confiança com a comunidade, criando uma relação de proximidade do governante com a população, a coisa pública é mais bem administrada.

De acordo com Matus, a governabilidade do sistema "expressa o poder que determinado ator tem para realizar seu projeto. É relativa a um determinado ator, às demandas ou exigências que o projeto de governo impõe a ele, e à sua capacidade de governo" (Matus, 1996a, p. 51). Nessa perspectiva, percebemos que existem dois elementos fundamentais para o desempenho de uma gestão: a governabilidade e a capacidade de governo, a qual se apresenta como o outro elemento de governo 
e que está diretamente ligado à capacidade de direção do ponto de vista técnico.

Em termos gerais, a capacidade de governo diz respeito justamente ao domínio que a equipe dirigente precisa ter das ciências e das técnicas de governo para direcionar as ações do governante de forma a que seja possível elevar a qualidade da gestão. Segundo Matus:

a capacidade de governo é uma capacidade de condução ou de direção e refere-se ao acervo de técnicas, métodos, destrezas e habilidades de um ator e de sua equipe de governo para conduzir o processo social a objetivos direcionados, dados a governabilidade do sistema e o conteúdo propositivo do projeto de governo (...), a capacidade de governo expressa-se na capacidade de direção, de gestão e de administração e de controle. (Matus, 1996, p. 52)

Em linhas gerais, estudar uma gestão pública, tendo em mente a ideia de triângulo de governo desenvolvida por Matus requer, primeiramente, que se conheça o projeto de governo, as ações propositivas que se pretende realizar; as bases de sustentação política do governante, a capacidade que o gestor tem para implementar projetos; e a capacidade técnica instalada que vai garantir aos projetos substância em termos de conteúdo no sentido de ações concretas que sejam eficazes na solução de problemas da sociedade. Dessa forma, o governante tem que ter clareza da necessidade de equilíbrio entre esses três elementos e da importância da dimensão política na sustentação da possibilidade de um bom desempenho governamental. Se a busca de equilíbrio deve ser a grande diretriz no processo de governo, é necessário o governante criar estratégias que lhe deem condições de manter o equilíbrio entre os mesmos. Estratégias essas que são o resultado de cálculos que o ator político faz no sentido de encontrar o caminho mais adequado (racional) para a concretização de seus objetivos.

Na literatura, podemos identificar o termo governança como sinônimo da capacidade de governo. Segundo Eli Diniz, o termo governança se refere a eficácia governamental, a capacidade de ação do governo, o que se revela a partir de três dimensões, qual seja, a capacidade de comando e de direção do governo; a capacidade de coordenação do governo entre os diferentes interesses e projetos políticos presentes na arena política; e a capacidade de implementação que requer por parte do governante a capacidade de mobilizar os recursos técnicos, institucionais, financeiros e políticos necessários à execução de suas decisões (Diniz, 1997).

De modo similar, Fábio Wanderley Reis entende que o termo governança diz respeito basicamente à capacidade de governo. Para ele, o conceito de governança, que se refere ao exercício dinâmico do ato de governar, apresenta a capacidade de coordenação, liderança, implementação e a capacidade de produzir credibilidade como seus elementos constitutivos, os quais são interdependentes. Dessa forma, a governança estaria intrinsecamente relacionada "a capacidade de propor e articular uma agenda política e gerar recursos necessários para a sua implementação" (Reis, 1994, p. 198).

Diante disso, podemos dizer que o conceito de governança diz respeito ao modo de operação do governo em torno da sociedade, ou seja, a capacidade de concretizar a agenda 
do governo, o que significa formular e tornar real essa agenda em termos de realizar ações que viabilizem os projetos e programas. Ao contrário do conceito de governabilidade, que se refere à caracterização das "condições institucionais e sistêmicas mais gerais que se dá o exercício do poder em uma dada sociedade, tais como a forma de governo, as características dos sistemas partidário e eleitoral, entre outras" (Diniz, 1997, pp. 38-39).

Diante dessa discussão, Santos (1997) chama a atenção para o fato de que é pouco importante, nos últimos anos, tentar diferenciar os conceitos de governabilidade e governança. Isso porque com a ampliação do conceito de governança, que passa a incorporar questões relativas a padrões de articulação e cooperação entre o Estado e a sociedade (no sentido de que para se ter uma administração eficiente é preciso garantir a operação democrática do Estado), torna-se cada vez mais difícil distinguir esses conceitos.

Para nossos propósitos analíticos, adotamos o termo "capacidade governativa", cuja definição sintetiza a discussão em torno desses conceitos, uma vez que engloba os aspectos operacionais do aparelho de Estado, assim como suas dimensões institucional, política e econômica. Para Santos, "a capacidade governativa se define como a capacidade de um sistema político de produzir políticas públicas que resolvam os problemas da sociedade (...), de converter o potencial político de um dado conjunto de instituições e práticas políticas em capacidade de definir, implementar e sustentar políticas" (Santos, 1997, p. 344).

A análise da gestão urbana supõe que, para dar conta de projetos de governo, governabilidade do sistema e capacidade de governo, se realizem alguns balanços em áreas que são fundamentais, uma vez que, ao avaliar o desempenho governamental, o balanço de "capacidade governativa" dá condições para o governante realizar mudanças que tenham por objetivo a sustentação do governo. Isso porque os balanços justamente levam em conta os elementos da governabilidade, dos projetos e da capacidade de governo. Nesse sentido, os balanços de uma gestão servem para apontar resultados de um governo, no sentido de um bom ou mau desempenho.

\section{Balanços de "capacidade governativa"}

Dentro dessa perspectiva, Carlos Matus diz que os resultados de um governo (que, inicialmente, para ser positivo necessita de métodos de planejamento que possibilite alcançar uma boa qualidade da gestão de governo) são ordenados em relação a três tipos de balanços de gestão: 1) o Balanço de Gestão Política, 2) o Balanço Macroeconômico e 3) o Balanço de Intercâmbio de Problemas Específicos. 
Estratégias de planejamento governamental para o " bom

governo" - CARLOS MATUS

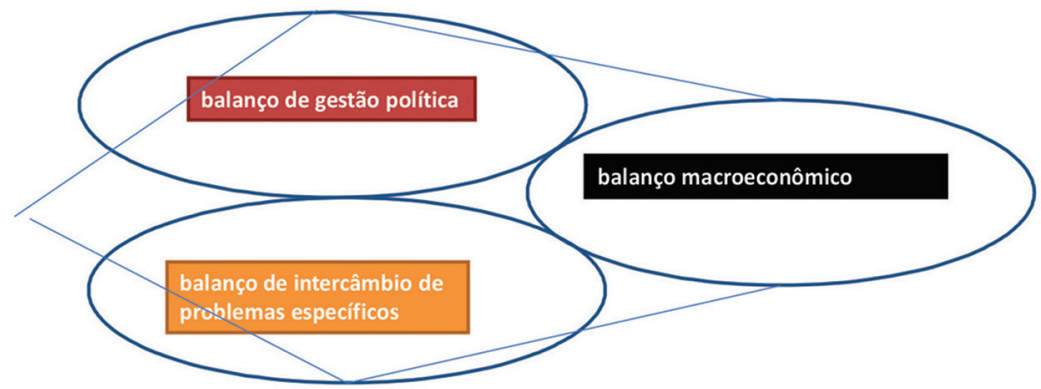

Fonte: Ilustração elaborada pelas autoras (com base em Matus, 1996).

De acordo com Matus (1996a, p. 30), o balanço de gestão política

sintetiza os resultados positivos e negativos alcançados no âmbito específico que responde ou não às demandas políticas dos atores sociais e da população em geral. Refere-se à ação do governante que incide sobre a qualidade da democracia, 0 respeito aos direitos humanos, a distribuição descentralizada do poder (...), a manutenção da legitimidade e da legalidade do governo.

Além disso, esse balanço apresenta-se intrinsecamente relacionado à imagem do governante, no sentido de fortalecimento ou não de seu capital político. Ou seja, os efeitos desse balanço refletem diretamente sobre as condições de governo, ou melhor, sobre a governabilidade, uma vez que essa supõe, por parte do governante, capacidade de manter democraticamente o papel das oposições, de incorporar e agregar os interesses organizados da sociedade, assim como de conseguir apoio político para implementar ações.

Nesse sentido, o governo tem que ser capaz de construir bases de sustentação política para manter um resultado positivo no balanço de gestão política, o qual é justamente um balanço em relação aos pontos positivos e negativos relacionados com a qualidade da democracia, ou melhor, um cálculo dos pontos positivos e negativos da gestão no sentido de aprovação ou não do ponto de vista da política democrática. Assim, o balanço de gestão política se relaciona com a ideia de capacidade de incorporação dos atores sociais ao contexto do governo. Logo, se o gestor não for capaz de incorporar novos atores a sua gestão, se não atuar na dimensão da participação, ou melhor, da partilha do poder decisório com a sociedade, o balanço 
de gestão política será negativo. Mas, ao contrário, se o governo respeitar o processo de democratização, descentralizando o poder político e administrativo para enfrentar os problemas levantados pela população, esse governo apresentará um saldo positivo no seu balanço de gestão política. Portanto, o balanço de gestão política está relacionado às respostas que 0 governo é capaz de dar às demandas políticas dos diferentes atores da sociedade.

Partindo dessa perspectiva, podemos dizer que como o padrão de relação entre 0 Estado e a sociedade mudou, e o novo padrão de intervenção está baseado numa suposta incorporação da sociedade ao processo decisório, o balanço de gestão política fornece os elementos para se "medir" a governabilidade, uma vez que o resultado desse balanço está relacionado diretamente com a capacidade de incorporar os atores políticos da sociedade.

Como já foi mencionado anteriormente, esse balanço também se relaciona com a capacidade de se produzir uma imagem positiva do governante, a qual necessita de apoios políticos para se concretizar. Isso porque o governante para manter uma liderança política precisa ter capacidade de implementar ações, as quais só se efetivam quando o governante obtém apoio para tal fim. Enfim, esse balanço é fundamental, porque ele aponta os elementos que se referem à governabilidade do sistema, tanto a capacidade de incorporação das demandas políticas de adesão conseguida junto aos atores políticos da comunidade, quanto a imagem do governante, de se produzir uma imagem positiva do mesmo, através do aumento de seu capital político, o que só se torna possível com o respeito a todos os aspectos que dizem respeito à democracia.
No que se refere ao outro tipo, o de balanço, macroeconômico, podemos dizer que ele visa a estabilização da economia e das bases de financiamentos das políticas públicas. Ou seja, o balanço macroeconômico tem a ver com políticas de estabilização, que possibilite o fortalecimento das bases de financiamento dos governos. Desse modo, é preciso que o governante seja capaz de dar conta dessa dimensão para que seja possível existir bases de financiamentos que viabilizem o projeto de governo. Isso demonstra a relação existente entre esse balanço e o projeto de governo, uma vez que a estabilização da situação econômica é essencial para o financiamento dos programas e projetos, porque sem bases de financiamentos os projetos não se efetivam, no sentido de sua implementação.

Em linhas gerais, o balanço macroeconômico "registra, em seus benefícios e custos, as consequências políticas do manejo macroeconômico e os resultados alcançados nas condições políticas vigentes, dentre as quais se destacam o crescimento econômico, o emprego, o equilíbrio do comércio exterior e a taxa de inflação" (Matus, 1996a, p. 31). É preciso ressaltar que essa noção de balanço macroeconômico é desenvolvida tendo em vista o nível central de governo, o que revela a necessidade de enfatizar que, para uma análise de governo local como a que este estudo pretende realizar, esse balanço vai criar as condições para as ações do governo serem implementadas, no sentido de garantir uma base mínima de estabilidade econômica e financeira que possibilite a realização dos programas.

0 balanço de intercâmbio de problemas específicos, por sua vez, "refere-se ao saldo de efeitos políticos positivos e negativos, gerado 
pelo enfrentamento dos problemas específicos valorizados pela população, por exemplo água potável, habitação, transporte urbano, eletricidade, etc." (Matus, 1996a, p. 31). A população sendo portadora de uma série de problemas elege o governante com a esperança de que esse apresente resultados para seus problemas, e esse balanço tem a ver com a capacidade do governo de enfrentar os problemas da comunidade, de dar respostas às questões colocadas pela população.

Dessa forma, o governante é um bom administrador se ele for capaz de manter expectativas positivas na comunidade, e só há expectativas positivas num contexto em que existe demonstração de capacidade de governo em determinadas áreas, ou seja, capacidade de transformar danos em ação. Partindo desse pressuposto, é necessário o gestor manter um certo equilíbrio entre os problemas provenientes da população e os que são respondidos no processo de governo, de modo que se estabeleça sempre um peso maior dos problemas solucionados a fim de alcançar um resultado positivo nesse balanço, ao invés de se criar um déficit político perante a população. 0 governo tem necessariamente que ser capaz de responder às demandas que vêm da sociedade. Governar é acima de tudo colocar as estruturas políticas administrativas em função dos problemas que a sociedade apresenta.

É necessário chamar a atenção para o fato de que Matus parte do princípio de que para a análise desses três tipos de balanços é preciso considerar dois critérios: a) a eficácia formal ou técnica, que responde à necessidade de enfrentar - com rigor, e respeitados os paradigmas científicos vigentes - os problemas próprios de cada balanço; e b) a eficácia material ou política, que responde à necessidade de considerar o poder político como um recurso escasso que não deve ser consumido sem limite em função de uma adesão infantil e tecnocrática ao primeiro critério, pois a perda do poder político pode levar, no extremo, à própria derrota do critério técnico baseado nas teorias científicas (Matus, 1996a).

Na concepção de Matus, é importante o analista de gestão ter em mente que na eficácia formal ou técnica entra a necessidade de se enfrentar com um certo rigor científico os problemas diagnosticados nos balanços. Esse critério chama a atenção para a relevância do conhecimento científico para respaldar os estudos dessa eficácia nesses balanços. Por sua vez, a eficácia material ou política se refere a importância de se ter sempre presente a ideia de que o recurso político é um recurso escasso no tempo, sendo necessário seu fortalecimento durante todo o processo de governo, uma vez que é difícil perceber o momento em que ele se esgota. Ou seja, o poder político que elege o governante, que faz um indivíduo governante, se fragiliza ou se esgota no tempo se o governante não for capaz de realimentar esse poder, o qual só se realimenta no momento em que o governante consegue dar respostas às questões levantadas pela população. Dessa forma, é necessário o gestor ter em mente que o recurso político não pode ser consumido sem limite, sendo preciso os gestores fortalecerem seu capital político, que como todo capital tende a se acabar se não for reproduzido, se não passar por um processo de produção/reprodução desse capital, o que está diretamente ligado com a capacidade de se fazer política.

Matus chama a atenção para o fato de que há uma defasagem, no tempo, entre esses 
dois tipos de eficácia ao longo do período de governo. A eficácia técnica só pode ser medida ao longo prazo, porque o resultado (positivo ou negativo) de uma aplicação técnica precisa de um certo tempo para se observar, enquanto a eficácia política é muito mais imediata, uma vez que o discurso de um governante ou uma medida tomada pelo mesmo é capaz de mudar o quadro político imediatamente, aumentando ou não o saldo do governante no que diz respeito ao capital político.

Em uma arena política desse tipo desempenha um papel importante o "empreendedor" ou "gestor" capaz de articular e compartilhar diferentes interesses cristalizados. Entretanto para que as políticas sejam viabilizadas e legitimadas é necessária também a existência de órgãos com respaldo técnico capazes de influenciar atores políticos relevantes.

\section{A inclusão de um novo balanço: de intercâmbio de problemas comuns}

Para se avançar nessa compreensão tendo por foco a realidade da metrópole brasileira haveria que se incorporar à análise um outro tipo de balanço de "capacidade governativa", com vistas à construção de uma boa governança metropolitana, visando solucionar o problema (ou a ausência) do governo metropolitano. A inexistência de um sistema de governo metropolitano é uma questão que dificulta a resolução dos problemas urbanos das maiores cidades do mundo. As áreas metropolitanas são áreas de grande dinamismo econômico, de grande concentração populacional e, por isso mesmo, de graves questões sociais, o que faz delas espaços de intensas contradições.

Hoje o crescimento e a riqueza do mundo estão cada vez mais concentrados em um número limitado de metrópoles. Elas não são apenas aglomerações humanas, são centros estratégicos de produção econômica, cultural e espaços referenciais para a dinâmica política de qualquer país. No entanto, as metrópoles se diferenciam de realidade para realidade. Como todo espaço social, elas são produto de uma história econômica e política, que define suas possibilidades, 0 ritmo de sua expansão e seu formato.

Na sociedade global, o crescimento e a riqueza estão cada vez mais concentrados em um número limitado de metrópoles, e as questões sociais se acumulam, principalmente nas áreas metropolitanas dos países de industrialização tardia, em que a dinâmica econômica é instável, e a capacidade produtiva extremamente, variável. Nesse contexto, as metrópoles contêm, ao mesmo tempo, o maior potencial de desenvolvimento do país e os mais graves problemas sociais.

É esse o cenário das áreas metropolitanas na maior parte do mundo, o que transforma as metrópoles em um problema também político. Isso porque elas constituem uma realidade territorial não contemplada pelo Direito, não são unidades formais de organização e, consequentemente, não têm uma estrutura de governo que responda pelos problemas que elas comportam. Como afirmam Borja e Castells (2004), as cidades metropolitanas são espaços urbanos onde a cidade real se confronta com a cidade formal, na medida em que, a cidade central (em torno da qual gravita a dinâmica metropolitana) esgota sua capacidade de resposta em relação à toda a região. 
Esse é o núcleo da questão da gestão metropolitana no Brasil. A metrópole não é uma unidade política, não tem as prerrogativas político-institucionais de uma unidade federativa, mas existe como espaço fundamental na dinâmica econômica na medida em que é o desenvolvimento das metrópoles que puxa a economia brasileira.

Se as metrópoles não são unidades políticas reconhecidas, o que são as metrópoles ou, de forma mais específica, as regiões metropolitanas? São áreas urbanas que, por força da necessidade de sistematização do planejamento das cidades, são definidas como espaços especiais pelas funções que exercem, pelo tamanho de sua população, pela inexistência de limites perceptíveis entre os municípios que ela incorpora, dentre outros critérios definidores. São, assim, arranjos institucionais e territoriais "atípicos" do planejamento governamental e da gestão urbana. Daí a nossa proposta de "planejamento adaptativo" inclui um novo balanço de "capacidade governativa" diretamente relacionado à realidade das áreas metropolitanas, tendo como referência inicial o "balanço global positivo" de Matus (1996a).

A literatura aponta que o debate sobre essa questão não é novo. Lefevre (2009), ao discutir o fracasso da constituição de instituições metropolitanas, recupera o debate entre reformadores e os defensores das escolhas públicas nos Estados Unidos nos anos 1960, quando a questão metropolitana já se evidenciava como problema concreto. 0 debate girava em torno da proposta reformista de instaurar uma institucionalidade metropolitana poderosa (a Garantua), capaz de gerir e solucionar os problemas metropolitanos apontados pelos reformistas: fragmentação institucional, suburbanização excessiva, elevados custos de urbanização, duplicação de serviços, desenvolvimento da segregação socioespacial e excesso de autonomia dos municípios. Tendo por referência o "combate de valores" em que prevalece a noção de interesse geral, interesse público, o coletivo à frente e a instituição democrática, e considerando a metrópole "uma nova comunidade política", propunham abolir o princípio da autonomia municipal; a redução das competências das comunas; o estabelecimento de competências metropolitanas no domínio do planejamento, advogando a importância do papel da coordenação metropolitana e a necessidade de recursos fiscais próprios e entidade política própria para geri-los.

Os adeptos da escolha pública, por sua vez negavam a ideia do território único afirmando que não há resposta única entre território funcional e institucional, criticando fundamente a ideia da Garantua. ${ }^{1}$ Tendo por referência o "combate de valores" em que prevalece a primazia do indivíduo sobre o coletivo e advogando a "liberdade de escolha onde viver e morar", recusa o termo fragmentação argumentado que a organização institucional baseada na multiplicidade de coletividades locais reflete o desejo da população. Reconhecem que os Estados Unidos têm sistema policêntrico ou de economia pública complexa, porém a multiciplicidade de coletividades é algo desejável. A Garantua é antidemocrática, burocrática, com estrutura grande demais, pesada, e não recomendável para uma institucionalidade que deve estar próxima dos cidadãos/eleitores. De todo modo, não contribui para a mobilização dos cidadãos a participar da vida política local.

Como posto, esse não é um debate técnico, mais um debate político, de "combate 
de valores" da sociedade americana dos anos 1960. Resgata-se a pertinência atual do debate e verifica-se quais outros elementos 0 atualizam e o revigoram. De modo um tanto paradoxal e desviante, um dos argumentos dos reformadores em favor da criação de um órgão metropolitano era o fato de que a metrópole nascente estava constituindo uma comunidade social e política. Hoje é por razões inversas, pois a metrópole se fragmenta no plano social e político. Por isso, muitos advogam por um dispositivo institucional que permitiria remediar essa fragmentação. Na mesma ordem de ideias, as questões de solidariedades territoriais estão hoje na agenda do governo metropolitano. Ainda, o sujeito das competitividades dos territórios em uma economia globalizada volta a dar força à questão institucional metropolitana. Ou seja, na competição da era global, àquela das metrópoles entre si, os municípios não são mais suficientes para produzir a força econômica, as amenidades e os equipamentos necessários para melhor se posicionar nessa louca corrida. As alianças e a cooperação institucional entre as coletividades locais (a metrópole é uma delas) são importantes para que certas políticas mudem de escala, para que estratégias comuns de desenvolvimentos sejam executadas, para que a promoção da área metropolitana seja eficaz.

Isso não significa que a questão institucional única seja a melhor alternativa nesse novo contexto. Entretanto, há muitos que consideram a adequação entre o território funcional e metropolitano e sua organização institucional. Não há certezas teóricas ou empíricas nessa questão.

Do mesmo modo, não existe nenhum balanço internacional recente da constituição de autoridades metropolitanas, de seu funcionamento e de seus resultados. Em compensação são numerosos os estudos; entretanto, poucas são as estruturas institucionais metropolitanas que se encontram no mundo, e no dizer de Brenner são de natureza "disparatada" em função do seu estatuto político. No mundo como um todo, muitas experiências foram feitas na busca de soluções sustentáveis para os governos das metrópoles.

As dificuldades de estabelecer consensos cooperativos é uma realidade também entre nós, e as tentativas de construção de arranjos institucionais que viabilizem a resolução dos problemas metropolitanos (como problemas de natureza comum a diferentes níveis de governo) envolvem desde mecanismos extremamente autoritários, que têm como base a força da lei, até a adoção de padrões democráticos de negociação.

Em alguns países, como o Brasil, de pouca tradição democrática, o encaminhamento das questões metropolitanas se dá a partir da criação de uma estrutura metropolitana que se configura por lei, acima dos governos municipais. Atualmente, no Brasil, a criação de regiões metropolitanas se efetua por lei estadual, como preconiza a Constituição de 1988, à revelia do interesse municipal.

Nesse contexto, os municípios são obrigados a atuar conjuntamente em uma série de funções previamente definidas. Uma estratégia nessa direção seria a criação do "município metropolitano", realidade muito semelhante a dos distritos federais, mas que no Brasil geraria enorme constrangimento político. Uma outra forma de encaminhar a resolução dos problemas metropolitanos, onde não existe uma autoridade metropolitana, é o uso de uma unidade administrativa de um nível 
administrativo superior, com a divisão (ou não) de competências, entre essa unidade e os municípios da aglomeração, situação que pode gerar conflitos.

Arranjos podem ser identificados também com a introdução de coordenações de base funcional, isto é, criação de mecanismos ou instituições para prestação de serviços ou funções específicas em territórios especialmente definidos. Recurso utilizado, por exemplo, em Barcelona e Nova York.

Finalmente, temos a experiência de algumas regiões metropolitanas onde, a despeito de não haver nenhum tipo de coordenação em nível supramunicipal, são estabelecidos mecanismos de cooperação entre os municípios com objetivos gerais ou específicos. Isso ocorre em situações de democracias consolidadas, em que o debate democrático e a consciência dos compromissos assumidos com as coletividades levam os signatários do poder a buscarem saídas que vislumbrem a sociedade mais ampla, num esforço de ação cooperativa, baseada na confiança e na participação de todos.

No entanto, a despeito dessa diversidade de possibilidades de enfrentamento da questão do governo da cidade metropolitana e da gestão dos problemas metropolitanos, uma constante geral ainda é o exercício por parte dos níveis de governo superiores de funções de planejamento global e estratégico, pela dificuldade da cooperação e da prestação de serviços de grande envergadura como: transportes, eliminação de resíduos, saneamento, meio ambiente, etc. É bom ter em mente que formatos de gestão que demandam a cooperação de muitos atores e agências constituem um problema de ação coletiva de um grande grupo. Como aponta a literatura, a cooperação nos grandes grupos tende a ter custos elevados e implica a construção de consensos entre os diferentes níveis de governo para que suas ações e recursos convirjam ao mesmo tempo para uma dada decisão (ver Souza, 2006, p. 173).

Como afirmam Borja e Castells (2004):

[...] a repartição de competências entre os distintos níveis de governo é uma questão complexa que depende tanto do tipo de organização metropolitana adotada, quanto da estrutura geral do Estado, das relações intergovernamentais, do grau de autonomia das autoridades locais, etc.

Diante de tudo isso é importante lembrar que nas regiões metropolitanas o conflito se sobrepõe ao consenso o que parece tornar ingovernáveis essas áreas. Ele tem origem em diferentes situações de incerteza, envolvendo: o financiamento das ações de âmbito metropolitano, a desconfiança em relação a uma possível perda de autonomia dos municípios, a possibilidade do aumento do gasto público e da burocracia e a própria definição do âmbito metropolitano, questão muito presente no caso brasileiro atual.

Sabemos que no Brasil a inexistência de arranjos institucionais em nível estadual dificulta atitudes de cooperação entre os municípios; que os conflitos partidários funcionam como obstáculos poderosos à integração das ações; e que o aprofundamento das relações intergovernamentais tende a ocorrer quando a sociedade, por intermédio de suas organizações, assume o papel de cimento dessas relações.

A importância de incluir o balanço de intercâmbio de problemas comuns no "balanço global positivo" de Matus, olhando a realidade metropolitana brasileira, está na tentativa de potencializar iniciativas já existentes no Brasil 


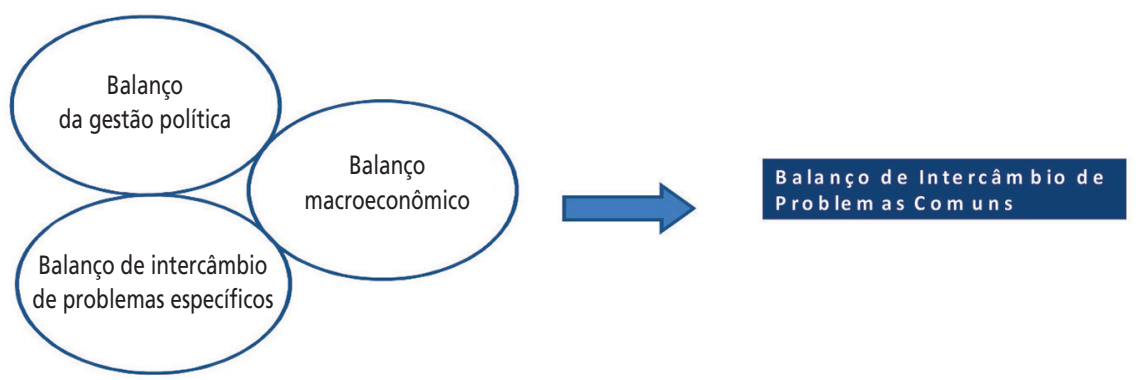

Fonte: Ilustração elaborada pelas autoras (com base em Matus, 1996a).

de constituição de pactos territoriais (como pactos políticos) para resolução desse impasse institucional. Assim como abrir, a partir do saldo desse balanço, novas possibilidades para melhoria das relações intergovernamentais visando a boa governança urbana.

Como nos ensina Matus (1996a), a arte e a técnica de governar consistem em produzir, mediante compensações, um balanço global positivo. Isso significa dizer que a qualidade da gestão governamental se apresenta no balanço político global, o qual necessita ser positivo para o governante não sofrer perda de capital político. Isso porque "um saldo negativo do conjunto da gestão representaria um saque contra o capital político do governante" (Matus, 1996, p. 34). Incluímos nesse balanço global um novo elemento, que dá respaldo para o tratamento dos problemas metropolitanos, como problemas territoriais de interesse comum.

Como vimos, a capacidade governativa tem a ver com a liderança política que 0 governante tem na comunidade como um todo, uma vez que o desempenho de governo não depende só das ações concretas que o governo é capaz de implementar, mas também da capacidade que o governo tem para manter uma taxa razoável de governabilidade, de administrar o processo de legitimação do poder político e de dar conta da dimensão política do desempenho governamental.

À medida que a gestão pública está sempre sendo avaliada pelo cidadão, para o governante ser considerado competente e eficiente ao término de seu mandato, faz-se necessário realizar uma gestão bem-sucedida, e para tanto é preciso ter saldos positivos nos balanços de gestão. Em se tratando dos municípios que compõem regiões metropolitanas, cabe ao governante compensar também os efeitos do balanço de intercâmbio de problemas comuns, de forma a que seja possível manter a sustentabilidade política da governança metropolitana. 


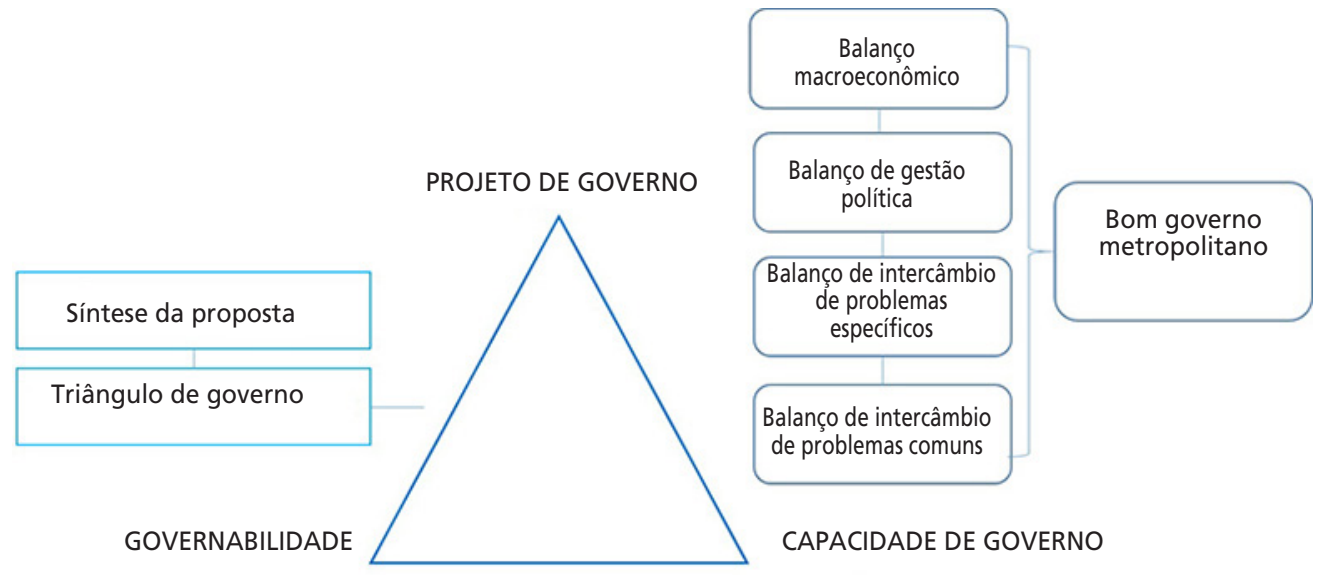

Fonte: Ilustração elaborada pelas autoras (com base em Matus, 1996).

Persiste um vazio institucional no que diz respeito à governança compartilhada, que,entendemos, deve ter como base de sustentação uma ação coletiva, fazendo com que diversos atores cooperem em um território para produzir o bem comum. Isso implica a necessidade da construção de consensos, no que diz respeito aos diversos objetivos dos órgãos de diferentes governos envolvidos, a fim de que suas ações e recursos convirjam simultaneamente para uma dada decisão.

\section{O Balanço de intercâmbio dos problemas comuns e o "mal público metropolitano"}

Visando contribuir no debate contemporâneo acerca da construção da governança metropolitana, introduzimos o conceito de "mal público metropolitano" (Lacerda, 2011) na análise do "planejamento adaptativo", conceito esse que, na nossa visão, permite refinar o entendimento dos problemas metropolitanos de coordenação da circunscrição territorial ("cidade metropolitana", Andrade e Clementino, 2007) no campo político-administrativo.

Em seu modelo de análise, Lacerda (2011) denomina "mal público metropolitano":

os custos compulsórios consumidos por um município em função de sua integração socioespacial a uma região metropolitana. Tais custos podem ser sanitários, habitacionais ou relacionados à execução das mais diversas políticas públicas, e são causados por condutas (ativamente perseguidas ou relativamente toleradas) de outros municípios na região. É parte integrante dessa definição a noção de que o consumo compulsório do mal público pode ser interrompido ou efetivamente reduzido via cooperação intermunicipal. Também pressuponho aqui que tais custos compulsórios são, em algum momento, percebidos pelos entes municipais. (Lacerda, 2011, p. 156) 
Concordamos com Lacerda (2011) quando ele parte do princípio de que o consumo compulsório do mal público pode ser interrompido ou efetivamente reduzido via cooperação intermunicipal, mas acrescentamos que, em se tratando de região metropolitana (cidade metropolitana), o consumo compulsório do mal público pode ser interrompido ou efetivamente reduzido via cooperação intergovernamental, porque outro ente da federação exerce, a nosso ver, um importante papel no processo de construção do "bem público metropolitano" - o governo estadual.

Na opinião de Lacerda (2011, p.164), no caso brasileiro, "a resolução pontual desses descompassos pelo governo estadual não é obvia e nem deve ser vista prima facie como a solução estável por excelência". Do ponto de vista analítico torna-se interessante identificar o nexo entre o "consumo do mal coletivo" e as estruturas de governança metropolitana. Uma saída seria que um ente supramunicipal no nível local assumisse (em maior proporção) os custos desse descompasso de consumo dos bens públicos, como, por exemplo, o estado federado, que no Brasil, assim como o município, é um ente federado em parceria com os municípios metropolitanos. $^{2}$

Como na gestão das políticas públicas, no Brasil contemporâneo, os três entes federativos (União, estados e municípios) assumem as chamadas competências comuns, tendo em vista 0 atendimento do interesse público, e, de acordo com o princípio da subsidiariedade, as atribuições que afetem dois ou mais municípios certamente se inserem no âmbito da competência do Estado, são os chamados interesses públicos intermunicipais ou estaduais; defendemos a tese de que o estado é um protagonista à construção técnico-política de governança metropolitana. Segundo Lomar, o princípio da subsidiariedade ressalta que:

[...] todas aquelas atribuições que possam ser exercidas pelo Município não devem ser exercidas pelo Estado ou pela União, aquelas que afetem dois ou mais municípios certamente se inserem no âmbito da competência do Estado; são os chamados interesses públicos intermunicipais ou estaduais. E aquelas questões mais abrangentes que afetem dois ou mais estados são os interesses interestaduais e, portanto, nacionais. É claro que essa divisão não é absoluta, porque na maioria das situações, esses interesses se interpenetram.

Concordamos com Wilson et al. (2010), quando, após análise das estruturas de governança metropolitanas em seis federações latino-americanas (Argentina, Brasil, Canadá, México, Estados Unidos e Venezuela) afirmam que:

[...] nos casos desses países federativos, sugerem que o caminho para estruturar a governança em áreas metropolitanas não deverá depender das iniciativas de governos federais e de reformas constitucionais, mas, sobretudo, deverá contar com estímulo ao desenvolvimento de arranjos entre governos locais, onde os governos estaduais e provinciais podem ter um papel importante.

Nossa proposta ressalta ainda mais a significativa importância do papel do governo estadual na resolução dos problemas metropolitanos, ou seja, do balanço de intercâmbio de problemas comuns. Considerando que, no Brasil, a Constituição em vigor (Art. 25) transferiu aos estados a competência para instituir regiões metropolitanas, e que 0 § 3.0 do art. 25 diz que "compete ao Estado integrar a 
organização, o planejamento e a execução de funções públicas de interesse comum" cabe a esse ente da federação, a nosso ver, assumir parte (ou mesmo a maior proporção) do "mal público metropolitano".

A importância do papel do estado na construção técnico-política da governança metropolitana pode se verificar também no Estatuto da Cidade (2001), uma legislação infraconstitucional, que orienta o estado a se respaldar no planejamento participativo à escala metropolitana; ou seja, o estado ao realizar determinadas intervenções que afetam o ordenamento territorial da metrópole deve se respaldar naquilo que chamamos de "planejamento adaptativo". 0 Art. 45 do Estatuto da Cidade (2001) afirma que, para garantir a gestão democrática da cidade, "os organismos gestores de regiões metropolitanas e aglomerações urbanas incluirão obrigatória e significativa participação à população e de associações representativas dos vários segmentos da comunidade, de modo a garantir o controle direto de suas atividades e o pleno exercício da cidadania". Esse ente da federação, o estado, deve no processo de planejamento (e intervenção) metropolitano, oferecer a oportunidade de ampla participação popular.

Além disso, estudos recentes demonstram que a grande maioria das regiões metropolitanas brasileiras padece de fragilidade institucional para estruturar mecanismos de governança metropolitana com condições de solucionar os problemas existentes na "cidade metropolitana", o que pode se explicar pela ausência de uma identidade metropolitana, que dificulta uma ação coletiva capaz de garantir a governabilidade e/ou a falta de incentivos dos governos estaduais.
Como o governo estadual deveria necessariamente cooperar para a redução ou eliminação do "mal público metropolitano" junto com os governos municipais, na nossa visão, será a partir das competências comuns, as quais devem ser realizadas a partir da promoção da cooperação entre as três esferas de governos (municipal, estadual e federal), utilizando dos instrumentos fiscais e legais.

Nossa proposta parte da realidade brasileira na qual o governo estadual cria as regiões metropolitanas e, mesmo tendo a prerrogativa de coordenar os processos de integração de seu planejamento de forma participativa na escala metropolitana, praticamente não tem avançado. Nos poucos casos de reestruturação institucional que lograram algum sucesso (pós a Constituição de 1988), o estado federado teve um papel de grande centralidade.

No entanto, a população das RMs, no Brasil, não está suficientemente organizada nem mobilizada para se incorporar, por exemplo, aos mecanismos institucionais de participação com uma identidade metropolitana em busca de uma ação coletiva, e isso representa um sério problema para uma governança metropolitana, e cabe aos governos estaduais e locais criar estratégias para produzir na cidade essa identidade territorial.

Segundo Souza (2009), "a marca do passado", pautada na dependência dos recursos e das decisões federais e na centralização, tem dificultado mudanças no desenho institucional das regiões metropolitanas e na rota das políticas públicas. A inexistência de uma sociedade organizada e de mobilização da mesma na direção da resolução dos problemas comuns dificulta a construção de saídas de natureza coletiva. 
A inexistência de uma identidade metropolitana, aliada a uma cultura cívica que empurre os cidadãos para a participação, tem dificultado a mobilização social nas regiões metropolitanas brasileiras, o que se justifica pela referência que os movimentos organizados ainda têm com a participação focalizada no imediatismo do espaço de moradia. As ações de natureza coletivas são expressões do espaço municipal, a interação quando ocorre é com as instituições municipais de governo e não ultrapassa as fronteiras (do ponto de vista político) das unidades territoriais formais na direção de uma atuação mais ampla. Para uma governança metropolitana faz-se necessário estabelecer relações intergovernamentais e sociais de um novo tipo, pautadas na ação coletiva.

Como já foi dito anteriormente, a ausência de arranjos institucionais compartilhados em nível estadual dificulta atitudes de cooperação entre os municípios; os conflitos partidários funcionam como obstáculos poderosos à integração das ações, e o aprofundamento das relações intergovernamentais tende a ocorrer quando a sociedade, através de suas organizações, assume o papel de cimento dessas relações. Por outro lado, as incertezas acerca do financiamento das ações de âmbito metropolitano, que pode gerar ou não um aumento do gasto público e da burocracia, e da perda de autonomia dos municípios, vêm sendo os principais constrangimentos para a realização de ações compartilhadas.

A ausência de estrutura de planejamento e de mecanismos permanentes de financiamento dos problemas comuns, na grande maioria das RMs, impõe limites e desafios para uma gestão compartilhada. Constatamos em pesquisas realizadas na região metropolitana de
Natal que o fato de um conselho municipal pertencer a uma região metropolitana não garante deliberações visando à solução de problemas comuns aos municípios que a compõem.

Na sociedade brasileira, experiências de cooperações federativas, ou melhor, de governança metropolitana por construção institucional (intermunicipais) são heterogêneas e incipientes, e a promulgação da Lei dos Consórcios Públicos, em 2005, constitui uma das primeiras iniciativas do Estado brasileiro. As variações na realidade dos municípios brasileiros, em termos de recursos financeiros, técnico e político para responder a suas responsabilidades impõem dificuldades para se estabelecer relações de cooperação, de partilha e de participação entre os diferentes atores.

A questão-chave para a formulação e implementação de políticas públicas na "cidade metropolitana", que garantam o atendimento dos direitos sociais do cidadão, é a criação de arranjos institucionais que superem a fragmentação institucional. Entendemos que "a superação da fragmentação institucional exige que a distribuição de competências entre os diferentes níveis de governo seja acompanhada pelo estabelecimento de arranjos de cooperação, que evitem o desperdício de esforços e permitam aproveitar economias de escala na provisão de bens e serviços públicos." Na concepção de Sol Garson, "nesse processo é importante identificar possíveis incentivos a serem oferecidos pelo governo central."

Na nossa visão, considerando a realidade brasileira, além de incentivos do governo central, cabe, principalmente, ao governo estadual criar incentivos à governança metropolitana. Ou seja, a gestão da "cidade metropolitana" requer a elaboração e implementação de 
um projeto metropolitano, que na concepção de Lefèvre (apud Garson, 2010, p. 11) "é um orientador da ação coletiva que se desenvolve nesses territórios, construídos a partir de elementos institucionais, financeiros e fiscais, políticos, geográficos e econômicos e elementos sociológicos e históricos".

No Brasil, a criação de arranjos institucionais metropolitanos que respondam ao balanço de intercâmbio de problemas comuns depende hoje da possibilidade de conjugar, em cada região, os elementos institucionais, financeiros e fiscais, políticos, geográficos e econômicos e os elementos sociológicos e históricos que constituem um projeto metropolitano (Garson, 2010, p. 43).

$\mathrm{Na}$ visão de Lomar, uma saída seria mudar a Constituição. Segundo ele,

[...] talvez, um processo complexo, complicado, porque é uma discussão sobre várias variáveis complicadas, inclusive $\mathrm{e}$, especialmente, à questão tributária. Mas acho que existe um grande espaço ainda meio inexplorado no campo da legislação ordinária, onde compete à União estabelecer uma legislação que oriente a atuação federal pelo menos na questão do desenvolvimento econômico e, portanto, embutida na questão de desenvolvimento econômico, considerar a questão do desenvolvimento urbano.

\section{E acrescenta:}

[...] o que é difícil é imaginar a elaboração de um plano em nível federal, que seja executado em cooperação, que a União transfira a execução para estados e municípios. Isso seria incompatível com o sistema federativo brasileiro. Então, é preciso ter um pouco de criatividade e pensar concretamente nas alternativas disponíveis, quer dizer, explorar o texto constitucional ao máximo, eu acho que há uma margem grande aí que ainda não foi bem suficientemente explorada.

\section{Como diz Rolnik,}

[...] acho que nós vamos ter que enfrentar isso e montar uma equação. Não vejo saída na base da construção de pactuações, em fóruns informais, que você toda hora tem que re-pactuar de novo. Acho o pacto de concertação lindo, maravilhoso, mas a gente não pode passar o resto da vida fazendo pacto de concertação. Chega um novo agente político que não fez parte do pacto e diz que não quer mais, desistiu. Nessa informalidade dos fóruns não dá mais. Então, acho que é difícil, é complexo, mas não consigo imaginar uma política nacional de desenvolvimento urbano sem enfrentar, claramente quem faz o quê, quem aprova o quê, quem põe dinheiro no quê, quem fiscaliza o quê. Só assim, fica decidido, e cada um inaugura a fitinha já que lhe cabe. Acho que é essa que deveria ser a nossa postura.

\section{Considerações finais}

0 modelo teórico de Lacerda (2011, p. 164) visou "compreender o fortalecimento dos vínculos entre a governança metropolitana e sua congênere sobre arranjos socioespaciais e dinâmica econômica". 0 recado básico dado pelo autor é que não dá para separar uma coisa da outra, na análise das RMs. Por isso consideramos necessário vincular o balanço de problemas metropolitanos ao "mal público metropolitano", à emergência e solução dos problemas cooperativos de planejamento e gestão. 
Como no Brasil contemporâneo os três entes federativos (União, estados e municípios) assumem as chamadas competências comuns, tendo em vista o atendimento do interesse público, para a construção técnico-política da governança metropolitana defendemos a ideia de que o estado deveria ser protagonista nesse processo, dada a sua condição de ser o ente da federação responsável pela criação e planejamento dessa escala territorial.

A fragilidade institucional das nossas RMs e a inexistência de um projeto metropolitano capaz de gerar uma ação coletiva, que possibilite uma cooperação entre os governos subnacionais e a não formação de uma consciência e identidade metropolitanas têm dificultado a redução ou eliminação do mal público metropolitano para a solução dos problemas comuns.
A ausência de estrutura de planejamento e de mecanismos permanentes de financiamento dos problemas comuns, na grande maioria das RMs, impõe limites e desafios para uma gestão compartilhada.

Em se tratando do Brasil, a responsabilidade do nível estadual de governo nas questões metropolitanas ressalta a necessidade de esse governo criar os arranjos institucionais, em nível estadual, capazes de gerar atitudes de cooperação entre os municípios, minimizando os conflitos partidários e aprofundando as relações intergovernamentais. Por outro lado, o governo estadual também deve gerar certezas acerca do financiamento das ações de âmbito metropolitano, que assegure a realização de ações compartilhadas, e que represente uma garantia de boas políticas públicas integradas.

\section{Maria do Livramento Miranda Clementino}

Universidade Federal do Rio Grande do Norte, Centro de Ciências Humanas, Letras e Artes, Departamento de Políticas Públicas. Natal/RN, Brasil.

clement@ufrnet.br

\section{Lindijane de Souza Bento Almeida}

Universidade Federal do Rio Grande do Norte, Centro de Ciências Humanas, Letras e Artes, Departamento de Políticas Públicas. Natal/RN, Brasil.

lindijane@cchla.ufrn.br 


\section{Notas}

(1) Trata-se de debate entre reformadores e defensores da ideia da "escolha pública" nos Estados Unidos (anos 1960) sobre o fracasso da constituição de instituições metropolitanas. Os reformadores propunham a criação da Gargantua (órgão de gestão governamental metropolitano), iniciativa veementemente criticada pela visão dos adeptos da "escolha racional" para evitar a duplicação de serviços e de coordenação da ação governamental sugeriam manter a organização institucional de economia pública local americana. Para esses últimos, a Gargantua seria antidemocrática, pois burocrática, com estrutura muito grande e pesada para estar próximo dos cidadão/eleitores. Além disso, não contribuiria para a mobilização dos cidadãos a participar da vida política local.

(2) A partir da Constituição de 1988, um novo arranjo federativo é estabelecido no país, o qual eleva o status Jurídico Constitucional dos Municípios. O Estado Brasileiro passou a ser formado pela união indissolúvel da União, estados federados, Distrito Federal e municípios, todos autônomos, nos termos da Constituição.

\section{Referências}

ALMEIDA, M. H. T. de (1995). Federalismo e políticas sociais. Revista Brasileira de Ciências Sociais. São Paulo, v. 28, n. 28, pp. 88-108.

ANDRADE, I. e CLEMENTINO, M. L. M. (2007). Descentralização e impasses da governança metropolitana. As Metrópoles e a Questão Social Brasileira. Rio de Janeiro, Revan, v. 1, pp. 239-258.

BORJA, J. e CASTELLS, M. (2004). Local y global: la gestión de las ciudades en la era de la información. Madri, Taurus.

BRENNER, N. (2003). La formación de la ciudad global y el re-escalamiento del espacio del Estado en la Europa occidental Post-Fordista. EURE Revista Latinoamericana de Estudios Regionales, v. XXIX, n. 86, pp. 5-36.

CLEMENTINO, M. do L. (2007). "Inovação no desenho das relações intermunicipais: o pacto territorial". In: LIMA, A. J. de (org.). Cidades brasileiras: atores, processos e gestão pública. Belo Horizonte, Autêntica.

(2008). Ordenamento e planejamento territorial: a falta que faz o Plano Metropolitano. Scripta Nova. Barcelona, v. 12, pp.109-141.

CLEMENTINO, M. L. M. e ALMEIDA, L. de S. B. (2011). Contribuições do planejamento técnico-político na construção da governança urbana e metropolitana. In: XIV ENANPUR. Anais. Rio de Janeiro.

DINIZ, E. (1997). "Governabilidade, democracia e reforma do Estado: os desafios da construção de uma nova ordem no Brasil". In: DINIZ, E. e AZEVEDO, S. (orgs.). Reforma do Estado e democracia no Brasil. Brasília, Editora Universidade de Brasília. 
GARSON, S. (2010). A Construção de projetos metropolitanos. Experiências internacionais de sistemas de governança metropolitana. Rio de Janeiro, Ippur/UFRJ/Faperj. (Relatório do Projeto OM/ Faperj).

LACERDA, A. D. F. de (2011). Ação Coletiva e Cooperação Intermunicipal em duas Metrópoles. Caderno CRH, Salvador, v. 24, n. 61, pp. 153-156.

LEFÈVRE, C. (2009). Governar as metrópoles: questões, desafios e limitações para construção de novos territórios políticos. Cadernos Metrópole. São Paulo, v. 11, n. 22, pp. 299-318.

MATUS, C. (1989). Senhor Presidente: planejamento, antiplanejamento e governo. Recife, Litteris. (1993). Política, planejamento e governo. Brasília, Ipea 143.

(1996). Estratégias Políticas: chimpanzé, Maquiavel e Ghandi. São Paulo, Fundap. (1996). Adeus, Senhor Presidente: governantes governados. São Paulo, Fundap.

MONTE-MÓR, R. L. de M. (2008). “Do urbanismo à política urbana: notas sobre a experiência brasileira”. In: MENDONÇA, J. e COSTA, G. (orgs.). Planejamento urbano no Brasil: trajetória, avanços e perspectivas. Belo Horizonte, C/Arte.

OSMONT, A. e LE BRIS, E. (2008). “Dissidence et secesión urbaines”. In: FRANCE, Ministère des Affaires étrangères e europeénnes. La Gouvernance Urbaine dans tous ses états. Paris, pp.30-33.

PUTNAM, R. (1996). Comunidade e democracia: a experiência da Itália moderna. Rio de Janeiro, FGV.

REIS, F. W. (1994). “Governabilidade e instituições políticas”. In: VELLOSO, J. P. dos R. (org.). Governabilidade, sistema político e violência urbana. São Paulo, José Olímpio.

(1995). Governabilidade, instituições e partidos. Revista Novos Estudos Cebrap, n. 41, pp. 40-59.

RIBEIRO, L. C. de Q. (2004). “As metrópoles e a sociedade brasileira: futuro comprometido?”. In: RIBEIRO, L. C. de Q. (org.). Metrópoles. Entre a coesão e a fragmentação, a cooperação e o conflito. São Paulo/Rio de Janeiro, Fundação Perseu Abramo/Fase - Federação de Órgãos para a Assistência Social e Educacional/Observatório das Metrópoles.

RIBEIRO, L. C. de Q. e SANTOS Jr., O. A. (2010). “As grandes cidades e a questão social brasileira: reflexões sobre o Estado de exceção nas metrópoles brasileiras”. In: CASTRO, E. de e WOJCIECHOWSKI, M. J. (orgs.). Inclusão, colaboração e governança urbana. Vancouver/Rio de Janeiro/Belo Horizonte, University British Columbia/Observatório das Metrópoles/Ed. PUC Minas

ROLNIK, R. (2001). Governar as metrópoles: dilemas da re-centralização. In: XXV ENCONTRO NACIONAL DA ANPOCS. Anais. Caxambu, MG.

SANTOS, M. H. de C. (1997). Governabilidade, governança e democracia: criação de capacidade governativa e relações executivo-legislativo no Brasil pós-constituinte. Dados - Revista de Ciências Sociais. Rio de Janeiro, v. 40, n. 3.

SANTOS, M. (1993). A urbanização brasileira. São Paulo, Hucitec.

(1996). Técnica, espaço, tempo: globalização e meio técnico-científico informacional. São Paulo, Hucitec. 
SEIXAS, J. e COSTA, P. (2009). Das cidades criativas à criatividade urbana criatividade e governança na cidade contemporânea. In: CONFERÊNCIA CONJUNTA DA EUROPEAN URBAN RESEARCH ASSOCIATION E DA URBAN AFFAIRS ASSOCIATION CITY FUTURES 09 - CITY FUTURES IN A GLOBALISING WORLD. Actas. Madri.

SOUZA, C. (2006). "Condições Institucionais de cooperação na Região Metropolitana de Salvador". In: CARVALHO, I. e PEREIRA, G. C. (coords.). Como Anda Salvador. Salvador, Edufba.

WILSON, R. H.; SPINK, P. K. e WARD, P. M. (2010). Metropolitan Governance in Americas. In: SEMINÁRIO INTERNACIONAL GOVERNANÇA URBANA E DESENVOLVIMENTO METROPOLITANO. Natal, RN, 1-3 setembro.

Texto recebido em 13/jan/2014

Texto aprovado em 16/out/2014 